Fourth International Symposium on Physics of Fluids (ISPF4)

International Journal of Modern Physics: Conference Series

Vol. 19 (2012) 190-195

(C) World Scientific Publishing Company

DOI: $10.1142 / \mathrm{S} 2010194512008744$

\title{
EXPERIMENTAL INVESTIGATIONS OF ADSORBED NATURAL GAS STORAGE SYSTEM WITH ENHANCED THERMAL MANAGEMENT
}

\author{
KAZI AFZALUR RAHMAN, WAI SOONG LOH, KIM CHOON NG \\ Department of Mechanical Engineering, National University of Singapore \\ 9 Engineering Drive 1, Singapore 117576 \\ mpengkc@nus.edu.sg \\ WONGEE CHUN \\ Department of Nuclear and Energy Engineering, Jeju National University \\ Jeju, Korea
}

\begin{abstract}
An adsorbed natural gas (ANG) storage system with internal thermal control, based on fin and tube type heat exchanger is investigated in this study. The adsorbent bed, which consists of Maxsorb III activated carbon packed in between copper fins and tubes, is demonstrated to study the storage capacity and thermal management of the ANG storage system. The cylinder is pressurized up to 35 bar and water is circulated through the tubes during charge process for quick removal of adsorption heat, thus to increase the storage capacity. Similarly, the adsorbent bed is heated up during discharge process to maximize the gas delivery. The current experimental arrangement presented shows higher storage capacity and better thermal management than the adsorbent bed without fin and tube arrangement.
\end{abstract}

Keywords: Adsorbed natural gas storage; fin and tube type heat exchanger; activated carbon.

\section{Introduction}

In recent years, adsorbed natural gas (ANG) has attracted much attention as a possible alternative to the conventional storage techniques such as compressed natural gas (CNG) or liquefied natural gas $(\mathrm{LNG})^{1-13}$. The ANG storage system operates at much lower pressure than the CNG method and stores gas at ambient condition with no cryo-cooling like the LNG storage. In the ANG storage system, natural gas is adsorbed by the porous adsorbents and it is subjected to thermal effects due to both heat of adsorption and desorption. Experimental investigations reported in the literature describe many different techniques to improve the thermal effects; however there is no enhanced solution found in the literature ${ }^{5-13}$. Therefore, this study is motivated to investigate the ANG storage system with enhanced thermal management. The adsorbent bed in this study is embedded with fin and tube type heat exchanger where the adsorbent is packed in the fin gaps and the coolant is circulated through the tubes. The experimental results demonstrate significant thermal enhancement of the adsorbent bed to maximize the storage capacity during charge process and increase the gas delivery during discharge process. 


\section{Brief Description of the Experimental Apparatus}

The experimental assembly of the ANG storage system mainly consists of (i) a stainless steel cylinder with flanges and end covers, (ii) a heat exchanger embedded activated carbon bed inside the storage cylinder, (iii) the gas charge/discharge assembly, (iv) the assembly for water circulation through the heat exchanger tubes, and (v) the data acquisition system. Fig. 1(a) shows the heat exchanger for the adsorbent bed before the activated carbon is packed. The activated carbon type Maxsorb III is packed in between the fins of the heat exchanger as shown in Fig. 1(b). The detailed surface characteristics of Maxsorb III and the adsorption parameters for methane/Maxsorb III pair are reported by Loh et $\mathrm{al}^{14}$. The stainless steel mesh (500 holes per inch) is wrapped around the heat exchanger to hold the activated carbon (AC) sample as shown in Fig. 1(c). Thermistor type temperature probes are placed in three different position of the AC bed for transient temperature measurement. The control valves, pressure regulators, gas flow controller, and safety relief valve are connected with necessary tubing and fittings (T's, elbows, unions, nipples etc.) to one of the cylinder end covers. The pressure transducer and RTD type temperature sensors are also connected to monitor the pressure and temperature of gas during charge and discharge processes. The top water header welded to another end cover. The on/off ball valves, water flow meters, and a water pump are connected with necessary fittings to the same end cover.

(a)

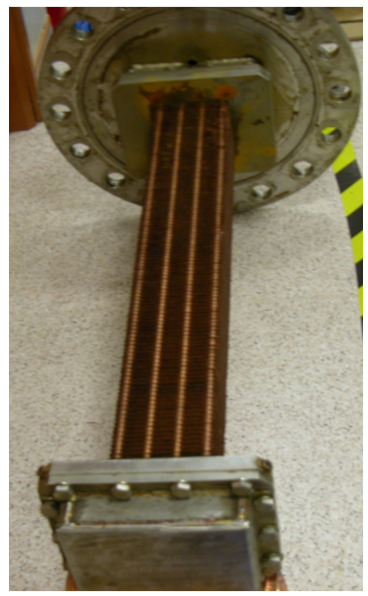

(b)
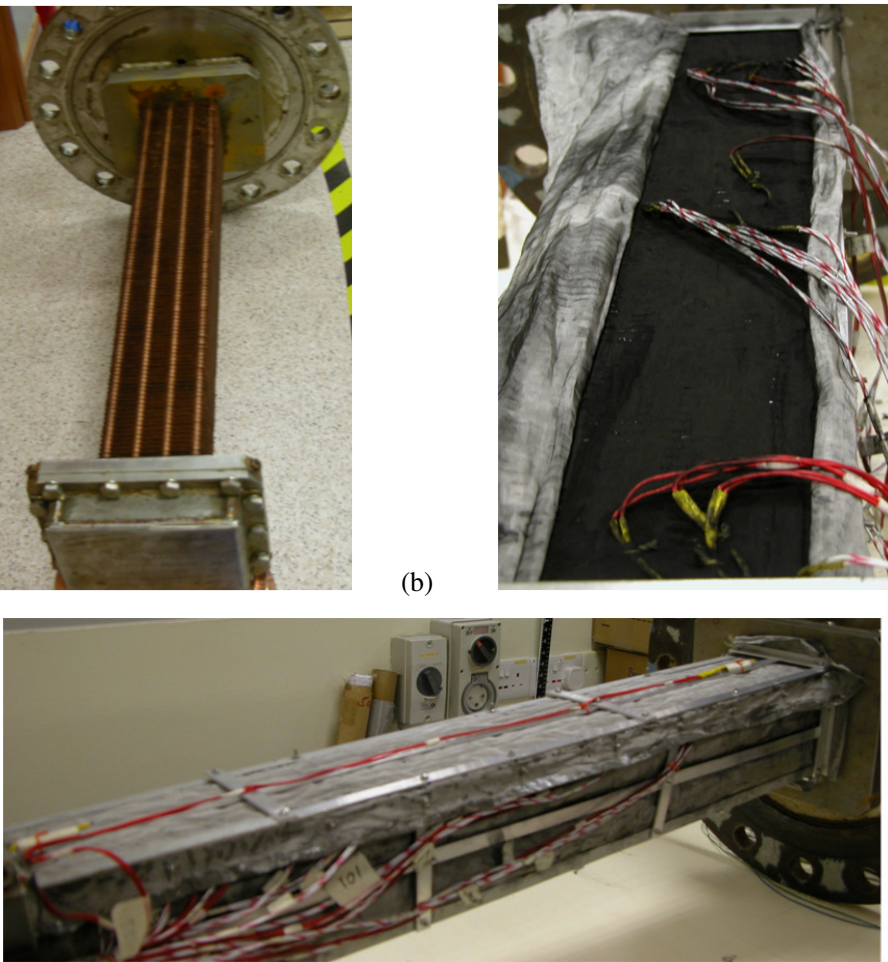

(c)

Fig. 1. The heat exchanger and the adsorbent bed before and after the activated carbon is packed. 
The water circulates from a temperature controlled bath to the heat exchanger through the headers inside the cylinder. A vacuum pump is also connected to the cylinder for evacuation during sample regeneration process. The stainless steel sintered filters of 0.5 $\mu \mathrm{m}$ size are connected in the vacuum and discharge line to prevent the fly-out of the AC particles during evacuation and discharge respectively. Fig. 2 shows the whole experimental assembly for the ANG storage prototype.

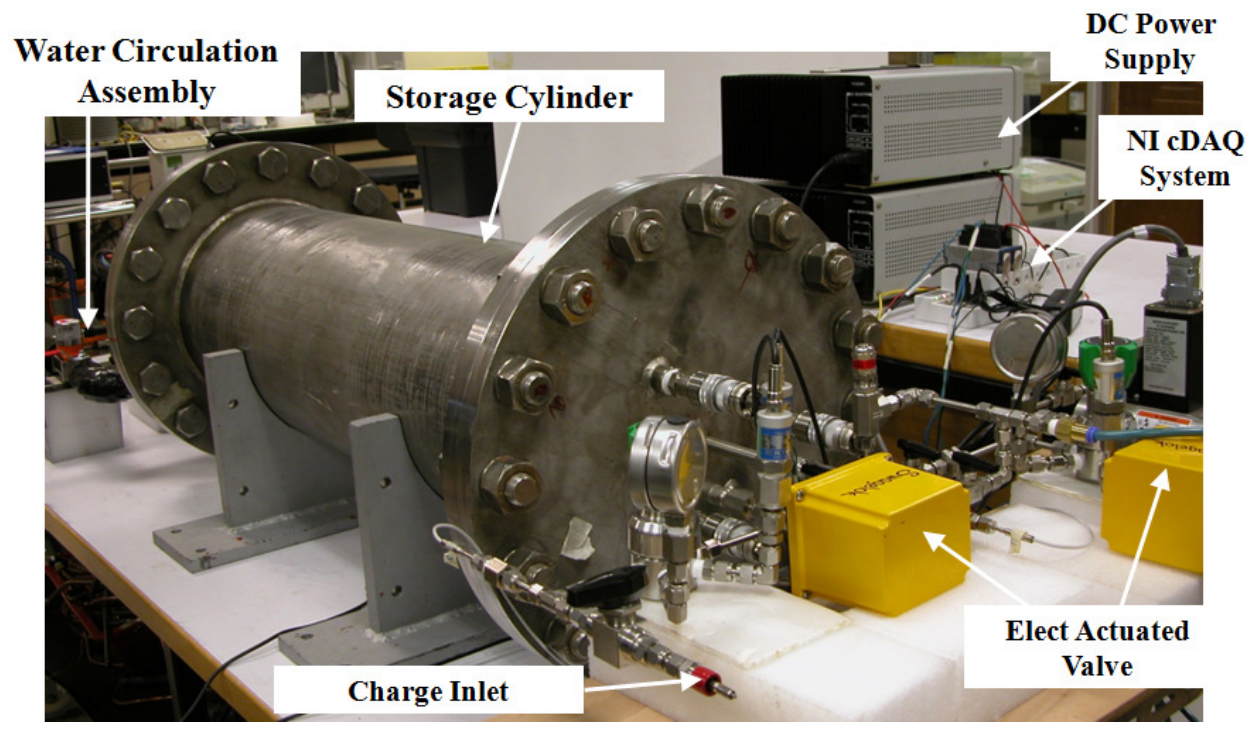

Fig. 2. The experimental assembly of the ANG storage system.

\section{Results and Discussions}

\subsection{Charge Process}

The methane is charged from a compressed gas cylinder and the charge pressure is regulated from atmospheric to about 35 bar. The gas inlet pressure and temperature is monitored during the charge process and it takes less than 10 minutes to reach the final pressure. The AC bed temperatures increase immediately after the charge process start that is mainly due to the heat of adsorption. The increase in temperatures is up to 50 to $60^{\circ} \mathrm{C}$ at different positions of the AC bed with no circulation of water. However, when water is circulated through the heat exchanger tubes, the AC bed temperatures rise only up to $35^{\circ} \mathrm{C}$ and also drop rapidly. Fig. 3 shows the AC bed temperature history at three different longitudinal positions against the charge time. It can be observed that the bed temperatures did not drop back to the initial temperature $\left(25^{\circ} \mathrm{C}\right)$ within 40 minutes of charge period in case of no water circulation whereas it takes less than 10 minutes when water is circulated. The heat of adsorption conducts to the circulating water through the fins and tubes and thus it causes quick temperature drop of the $\mathrm{AC}$ bed. Water of $25^{\circ} \mathrm{C}$ is 
circulated at rate of $0.9 \mathrm{~L} / \mathrm{min}$ through the tubes of ID $8 \mathrm{~mm}$ that generates the turbulent flow and thus enhances the heat transfer.

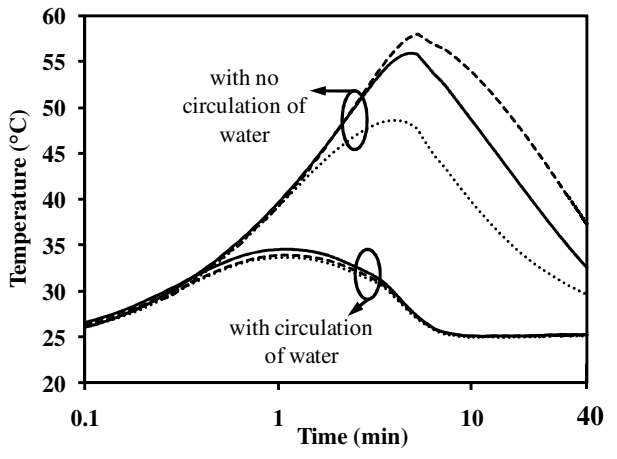

Fig. 3. Temperature history of the AC bed during charge process

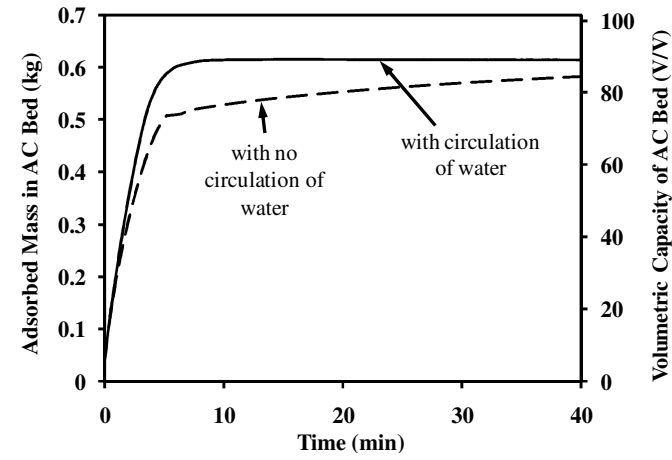

Fig. 4. The amount of adsorbed mass in the AC bed during charge process

Fig. 4 shows the amount of adsorbed mass in the AC bed during the charge process. The adsorbed mass for the experimental operating conditions are evaluated using the adsorption parameters for methane/Maxsorb III pair reported by Loh et $\mathrm{al}^{14}$. It can be seen that the AC bed attains its maximum capacity of gas adsorption within 10 minutes of the charge period when water is circulated to remove the heat of adsorption. This is because of the $\mathrm{AC}$ bed temperature and the cylinder pressure reaches quickly the steadystate. Although the valve remains open for the whole charge period, there is no significant increase of the adsorbed mass after 10 minutes of charge. On the other hand, it takes longer time to reach steady temperature with no circulation of water and thus the storage capacity of the AC bed does not maximized and the charge period is elongated to achieve the maximum capacity. It is evaluated that the AC bed losses about $17 \%$ of the storage capacity if the charge period continues for 10 minutes and there is no water circulation to remove the heat of adsorption.

\subsection{Discharge process}

The gas is discharged at a rate of $0.5 \mathrm{~g} / \mathrm{sec}$ that is maintained by the mass flow controller. Before the discharge process to start, the $\mathrm{AC}$ bed is maintained at an equilibrium temperature of $25^{\circ} \mathrm{C}$ and the cylinder inside pressure is kept at 35 bar. Figure 5 shows the measured temperatures of the $\mathrm{AC}$ bed at three different positions during discharge process when there is no circulation of water through the heat exchanger tubes. The bed temperature decreases gradually because of the endothermic desorption process and drops until very low temperature as plotted in Figure 5. The low temperature of the AC bed increases gas retention and thus lessens the delivered amount of gas. The similar discharge processes are again performed with water circulation through the heat exchanger tubes. The water inlet temperature is maintained at $25^{\circ} \mathrm{C}$ and $80^{\circ} \mathrm{C}$ during each discharge process. Heat from the flowing water conducts to the adsorbents through the tubes and fins. Thus, the bed temperature remains almost constant at $25^{\circ} \mathrm{C}$ in one case 
and increase up to $80^{\circ} \mathrm{C}$ and then remains steady in another case. The delivered capacity of methane is increased in both the cases.

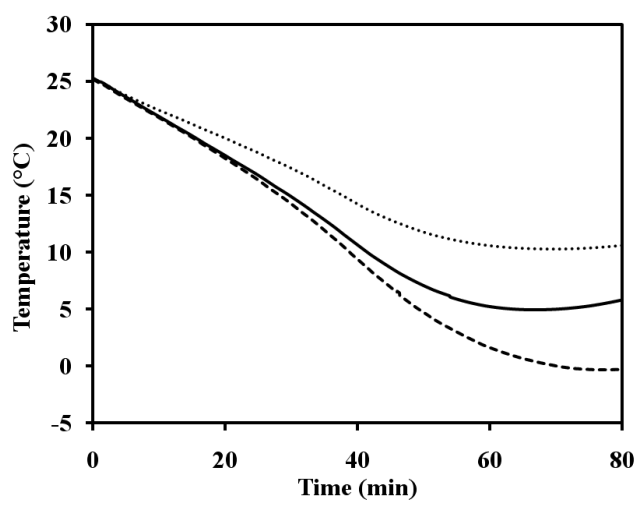

Fig. 5. The AC bed temperatures during discharge with no circulation of water

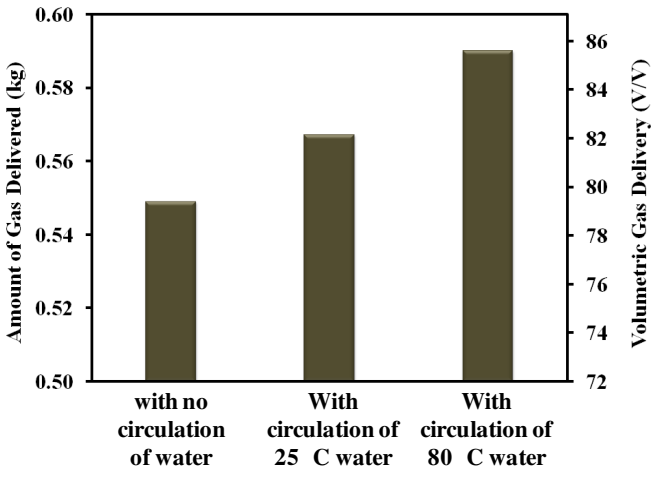

Fig. 6. The delivered amount of gas in discharge process

Figure 6 shows the bar plot of delivered amount of gas for all the three cases. It can be seen that the gas delivery is increased about $7 \%$ by circulating hot water, i.e. increasing the $\mathrm{AC}$ bed temperature during discharge process. Therefore, it can be said that the insertion of fins and tubes in the $\mathrm{AC}$ bed provide considerable enhancement in both the storage capacity and the gas delivery.

\section{Conclusions}

The ANG storage system is experimentally investigated for enhanced thermal management of the adsorbent bed based on finned type heat exchanger. The storage capacity of the adsorbent bed is increased by $17 \%$ with shorter charge period due to quick removal of heat of adsorption. The delivered amount of gas is also increased by $7 \%$ by supplying heat during discharge process. Thus, the overall capacity of the adsorbent storage system is improved by $24 \%$ in storing and delivering gas. However, the volume occupied by the fins and tubes is about $13 \%$ of the AC bed volume for the current heat exchanger design which is necessary to be optimized for effective thermal enhancement.

\section{Acknowledgments}

The authors' gratefully acknowledge the financial support given by grants (R33-2009000-101660) from World Class University (WCU) Project of the National Research Foundation, Korea, (R265-000-268-305) from A*STAR/MPA, Singapore and (R265000-286-597) from King Abdullah University of Science and Technology, KSA.

\section{References}

1. K. A. Rahman, W. S. Loh, A. Chakraborty, and et al., Appl. Therm. Eng. 31, 1630 (2010).

2. R. B. Rios, M. Bastos-Neto, M. R. Amora Jr., and et al., Fuel. 90, 113 (2011).

3. M. J. M. da Silva and L. A. Sphaier, App. Energy, 87, 1572 (2010). 
4. J. P. B. Mota, Adsorbed natural gas technology, Springer: Netherlands. 177-192 (2008).

5. I. A. A. C. Esteves, M. S. S. Lopes, P. M. C. Nunes and J. P. B. Mota, Sep. Purif. Tech. 62, 281 (2008).

6. A. Sáez and M. Toledo, App. Therm. Eng. 29, 2617 (2009).

7. S. C. Hirata, P. Couto, L. G. Lara and R. M. Cotta, Int. J. Therm. Sci. 48, 1176 (2009).

8. R. Basumatary, P. Dutta, M. Prasad and K. Srinivasan, Carbon, 43, 541 (2005).

9. X. D Yang, Q. R. Zheng, A. Z. Gu and X. S. Lu, App. Therm. Eng. 25, 591 (2005).

10. O. Pupier, V. Goetz and R. Fiscal, Chem. Eng. Proc. 44, 71 (2005).

11. S. Biloe, V. Goetza and S. Mauran, AIChE J. 47, 2819 (2001).

12. L. L. Vasiliev, L. E. Kanonchik, D. A. Mishkinis and M. I. Rabetsky, Int. J. Therm. Sci. 39, 1047 (2000).

13. K. J. Chang and O. Talu, App. Therm. Eng. 16, 359 (1996).

14. W. S. Loh, K. A. Rahman, A. Chakraborty, and et al., J. Chem. Eng. Data, 55, 2840 (2010). 